\title{
Minimally invasive hysterectomy for benign disease: our experience study
}

\author{
Talakere Usha Kiran, Rajshree Dayanand Katke*
}

Department of Obstetrics and Gynaecology, Cama and Albless Hospital, Grant Government Medical College and Sir J. J. Group of Hospitals, Mumbai, Maharashtra, India

Received: 24 May 2016

Accepted: 13 June 2016

\section{*Correspondence:}

Dr. Rajshree Dayanand Katke,

E-mail: drrajshrikatke@gmail.com

Copyright: (C) the author(s), publisher and licensee Medip Academy. This is an open-access article distributed under the terms of the Creative Commons Attribution Non-Commercial License, which permits unrestricted non-commercial use, distribution, and reproduction in any medium, provided the original work is properly cited.

\section{ABSTRACT}

Background: The incidence of hysterectomy in India ranges from 7-8 \% and 60\% of major gynaecological surgeries are hysterectomies at government teaching institutions. The objective of this study was to assess feasibility and safety of laparoscopic hysterectomy.

Methods: It was a retrospective case series. Study duration was two years. Setting was at Cama and Albless hospital which is a government hospital affiliated to grant medical college, Mumbai. Cases with benign indication for hysterectomy were which were unsuitable for vaginal approach were assessed and those deemed suitable for laparoscopic approach were selected. Total laparoscopic approach was used to perform hysterectomy. Patient demographics and outcome measures were analyzed. Outcome measures included duration of surgery, length of postoperative stay, estimated blood loss, complication rate and laparotomy conversion rates.

Results: It was a two year study period. Total number of women who underwent hysterectomies during this period for benign indications were 303, out of which 146 were done by vaginal route, 126 by abdominal route and the remaining $35(22 \%)$ were done by laparoscopic route. Main indication was dysfunctional uterine bleeding not responding to medical management. Median age of patients was 43 years, majorities were parous and none of them were obese. Uterine size ranged from normal size to 16 weeks. Duration of surgery was between 1.5-2.5 hours with an estimated blood loss of less than $100 \mathrm{ml}$ in $2 / 3^{\text {rd }}$ of them. Median duration of postoperative stay was 7 days. The major complication and laparotomy conversion and readmission rates were nil.

Conclusions: Laparoscopic hysterectomy was well accepted and was found to feasible and safe in our setting.

Keywords: Laparoscopic hysterectomy, Vaginal route, Postoperative

\section{INTRODUCTION}

The incidence of hysterectomy in India ranges from 7-8\% and $60 \%$ of major gynaecological surgeries are hysterectomies at government teaching institutions. ${ }^{1-3}$ Hysterectomies for DUB with no or minimal uterine descent are mostly by abdominal route unless the surgeon is experienced to do these vaginally. Laparoscopic approach has the advantages of converting an abdominal route to minimally invasive route in cases unsuitable for vaginal route either due to lack of operator skill or operative complexities such as larger uterine size, adhesions, fibroids, previous surgeries etc. It also gives a better access to remove ovaries. ${ }^{4}$

In our set up we started service for laparoscopic hysterectomy 2 years back and would like to share our initial experience with others.

\section{METHODS}

This is a retrospective case series of minimally invasive hysterectomy at Cama and Albless hospital, affiliated to government grant medical college, Mumbai, Maharashtra, India between the period of 2014 to 2016. 
All cases were jointly operated by the two gynaecological surgeons.

All patients who had an indication for hysterectomy underwent anesthetic assessment to check suitability before posting for surgery. Cases of uterine prolapse and those deemed feasible for vaginal route were excluded from the study. The rest of the cases who were for abdominal route were reassessed based on uterine size, previous abdominal surgeries, associated comorbidities to rule out contraindications for laparoscopy.

Cases with uterine size more than 18 weeks, multiple fibroids, multiple abdominal surgeries and severe medical conditions which made them unsuitable for laparoscopic approach were excluded from the laparoscopic group and were offered abdominal route. Cases with one or two previous caesarean sections were offered laparoscopic option. Patients who refused laparoscopic route were posted for abdominal route.

All these patients were counselled in detail about the hysterectomy procedure and its complications and in specific about the advantages and risks of laparoscopic approach. They all had a choice to refuse laparoscopic approach and choose abdominal route.

Standard procedure details for laparoscopic hysterectomy used were as follows: Veress needle entry for initial abdominal insufflation was used. In cases of previous surgeries, suspected adhesions and failed Veress needle entry, Hassan technique was adapted. Routinely four ports were used, one $10 \mathrm{~mm}$ umbilical, two $5 \mathrm{~mm}$ lateral (one on either side) and one $5 \mathrm{~mm}$ suprapubic. In cases with uterine size more than 12 weeks, an extra $10 \mathrm{~mm}$ port midway between umbilical and xiphisternum was used to get a better panoramic view. Thirty-degree laparoscope was used. Bipolar diathermy was used for coagulating the pedicles and mono-polar diathermy scissors were used for dissection and cutting. Vaginal cup manipulator and hydro dissection was used to aid dissection of bladder and cut the vaginal cuff. Total hysterectomy was performed in all cases and the specimen was removed through vaginal route. Vaginal vault was sutured from vaginal side and not laparoscopically as it was easier and less time consuming. Final hemostasis was checked laparoscopically and rectus sheath of $10 \mathrm{~mm}$ ports were closed with vicryl and skin of all ports were closed with monocryl sutures.

After the two-year period, data was retrospectively collected from the patient's case notes which consisted of preoperative, intraoperative and postoperative course, anesthetic notes and operation theatre register. Data regarding age, parity, weight of the patients, clinical presentation, indication for hysterectomy, clinical and ultrasound findings, comorbidities, date of admission, date of operation, date of discharge, length of stay, intraoperative or postoperative complications if any, estimated blood loss during surgery and blood transfusion if required was collected. It was analyzed using descriptive statistics on SSPS version 20.

\section{RESULTS}

It was a two-year study period. Total number of women who underwent hysterectomies during this period for benign indications were 303 , out of which 146 were done by vaginal route, 126 by abdominal route and the remaining 35 (22\%) were done by laparoscopic route.

Patient acceptance was not an issue as only minority refused.

The main indication for hysterectomy in these patients was dysfunctional uterine bleeding not responding to medical treatment. Two patients had menorrhagia with fibroid uterus and two with recurrent postmenopausal bleeding (Figure 1).

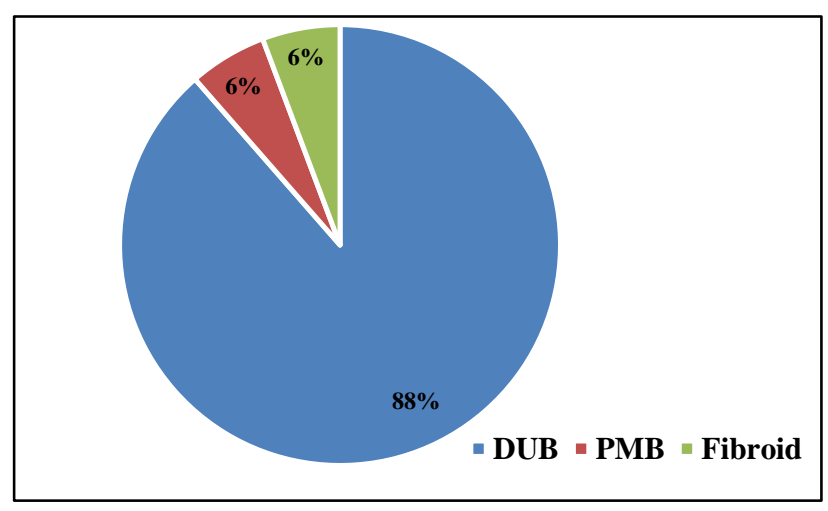

Figure 1: Indications for hysterectomy.

Majority of the women were in reproductive middle age group of 35-45 (Table 1).

Table 1: Age.

\begin{tabular}{|ll|}
\hline Age group & Number=N $(\%)$ \\
\hline$<35$ & $3(8.5 \%)$ \\
\hline $35-45$ & $20(57 \%)$ \\
\hline$>45$ & $12(34.5 \%)$ \\
\hline
\end{tabular}

Median weight of the patients was around $52 \mathrm{~kg}$ and the maximum weight was $58 \mathrm{~kg}$. Majority were parous $[\mathrm{N}=29(82 \%)$ with parity between 1-3]. Only three were nulliparous. Twelve (34\%) had medical comorbidities such as hypertension, diabetes mellitus and thyroid disorder, which were well controlled before surgery and $21(60 \%)$ had previous abdominal surgeries, such as cholecystectomy, caesarean section, appendicectomy, puerperal/interval tubal ligations.

Length of surgery ranged between 1.5-2.5 hours with no intraoperative complications. 
Estimated blood loss (Figure 2) was less than $100 \mathrm{ml}$ in majority of our patients $(63 \%)$. Only one patient had blood loss of $2000 \mathrm{ml}$

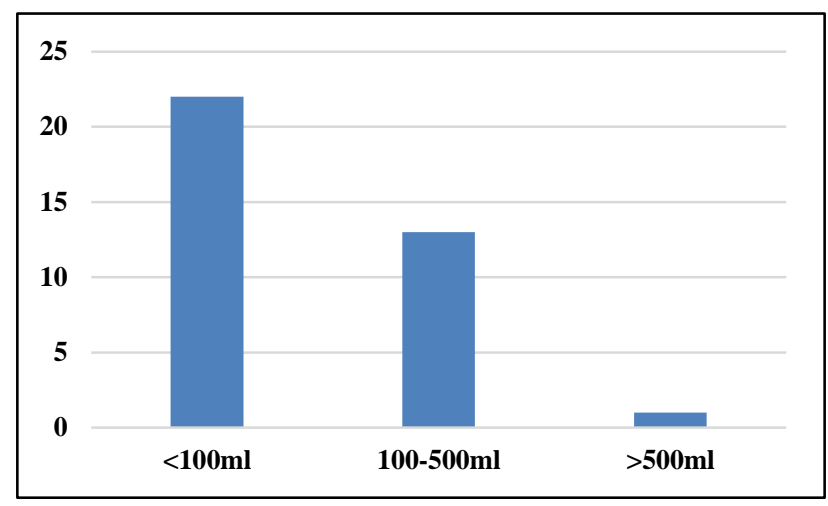

Figure 2: Estimated blood loss

Thirteen (37\%) of them received one unit of blood transfusion and one received 4 units of transfusion.

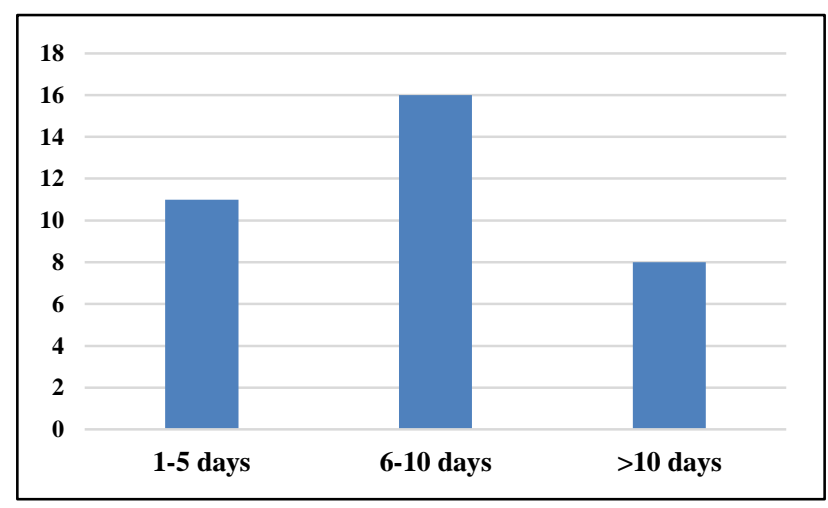

Figure 3: Duration of postoperative stay.

Median duration of postoperative stay was 7 days. Eleven (31\%) patients stayed less than 5 days in the hospital postoperatively (Figure 3).

Four patients had minor postoperative complications such as umbilical wound infection, persistent vaginal discharge, abdominal would seroma and abdominal distension ad paralytic ileus.

Laparotomy conversion and readmission rates were nil.

\section{DISCUSSION}

With laparoscopic approach, we were able to avoid the abdominal route in $22 \%$ in cases where vaginal route was deemed either difficult or not possible. It is a well-known fact that vaginal route should be the first choice and laparoscopic route offers an added advantage in cases where vaginal route is difficult due to complexities such as previous multiple surgeries/adhesions, increased uterine size and adnexal masses as it decreases the difficulty without having to open the abdominal route. ${ }^{4}$
We are confident that once the service is well established, the number of women for whom we can offer laparoscopic route will increase with the experience of the team providing the service.

Dysfunctional uterine bleeding not responding to medical management is one of the common reasons for hysterectomy worldwide although this indication has come down with the advent of other procedures such as endometrial ablation and levonorgestrel IUCD. ${ }^{9}$

However, in our setup, this is still remains one of the most common indication, as we do not have access to levonorgestrel IUCD and endometrial ablation procedures due to financial constraints. The other common indication is fibroid uterus with menorrhagia or pressure symptoms in our population. Fibroids are quoted as the commonest indication for hysterectomies by most studies but were the second common in our sample as those with larger fibroid were excluded from our study as this was a pilot service, we did not include larger fibroids to give margin for safety and learning curve of the team. ${ }^{3,10,11}$ In addition to this, we did not have a morcellator which limited our ability to take larger uterine specimens through vaginal route. With advancing time, we are sure hysterectomy for fibroids will be done more frequently by laparoscopic route in our setting.

The age group of our patients was in the common reproductive age group of 35-45 with median age being 43 years, which is the common age group presenting with DUB. Mean age quoted by other studies is slightly higher than ours. ${ }^{3}$

Most of our patients being from the lower socioeconomic status were in the average weight category which in fact facilitated our procedure laparoscopically. Laparoscopic route for overweight patients although poses operative difficulties, is a better option as it gives better operative vision and almost negates wound dehiscence which they are at risk. ${ }^{12-16}$

Length of surgery was slightly longer than our vaginal and abdominal procedures. There is a variation in the length of surgery for laparoscopic procedures quoted by other studies and some of the reasons are operator experience, uterine size and BMI. ${ }^{17}$ In our study the main variable was the team's experience as this was a pilot service.

We did not calculate the total length of stay in hospital as many of our patients come from distant rural areas and need longer preoperative stay for investigations, fitness, to arrange date for surgery and prefer to get it done by staying admitted at the hospital, as it is cost effective for them.

So our length of stay was calculated as the postoperative stay. One of the main advantages of laparoscopic route is the reduction in the length of stay at hospital which is not 
only beneficial for patient but also for the hospital and saves cost. ${ }^{18}$

This is not strongly evident from our study due to the sample population we represent. Patients prefer to stay till the histology is available for the uterine specimen in our population as to come back for the same is much more expensive in terms of time, effort and cost. As our histology reports are available between 7-10 days our post-operative stay is reflected in this. However, a small number did go home in four days which is an improvement on our abdominal hysterectomies as they prefer to go home only after suture removal which happens on either day 5 or 7 depending on the type of incision.

Conversion to laparotomy rates can be as high as $4-7 \%$ and are found to be influenced by bigger uterine size, intra-abdominal adhesions and increased BMI. Major complications during a laparoscopic hysterectomy are injury to urinary tract, bowel injury or a major blood vessel. $^{18-20}$

In our study the negative laparotomy and major complication rate phase was commendable although our sample numbers were small. One of the reasons for this is the stringent criteria used in selection of cases. This is one of the most important factors which can change the safety of laparoscopic approach if not adhered to stringently. This criteria, however is not fixed and can be relaxed as the experience of the team increases. ${ }^{20}$ It is important to revisit these criteria at regular intervals, so as to be able to balance the service provision and safety.

Our estimated blood loss was not only reasonably comparable with abdominal and vaginal procedure but in fact quite less ranging from 70 to $300 \mathrm{ml}$ in all except one who had excessive bleeding and required 4 units of transfusion. The quoted blood loss figures in the literature show that laparoscopic surgery definitely is beneficial in terms of blood loss as compared to abdominal surgery. ${ }^{21}$ The reason probably is the use of diathermy as the main modality for pedicles which reduces the blood loss.

As most of our patients came from rural and lower socioeconomic strata, one of the advantages with laparoscopic approach was the shorter time that they needed to be cared for once they got back home and lesser time it took for them to get back to their working life style, which in turn was savings for the family. Although this was not uniformly documented in our follow ups, it was the feedback which we received from most of our patients which is reflected in other studies. ${ }^{18}$

The other advantage of this service was that our trainees had more laparoscopic surgical exposure and training which made them more confident in laparoscopic procedures.

\section{CONCLUSION}

We conclude that our service of laparoscopic hysterectomy was successful and safe. It was accepted by our patients well and was found to be not only safe but also beneficial for our patients in terms of post op recovery and returning back to their working life style sooner.

\section{Funding: No funding sources \\ Conflict of interest: None declared}

Ethical approval: The study was approved by the Institutional Ethics Committee

\section{REFERENCES}

1. Singh A, Arora AK. Why hysterectomy rate are lower in India? Indian Journal of Community Medicine. 2008;33(3):196-7.

2. Desai S, Sinha T, Mahal A. Prevalence of hysterectomy among rural and urban women with and without health insurance in Gujarat, India. Reproductive Health Matters. 2011;19(37)42-51.

3. Pandey D, Sehgal K, Saxena A, Hebbar S, Nambiar J, Bhat RG. An audit of indications, complications, and justification of hysterectomies at a teaching hospital in India. International Journal of Reproductive Medic Volume. 2014:279273:6.

4. Johnson N, Barlow D, Lethaby A, Tavender E, Curr E, Garry R. Surgical approach to hysterectomy for benign gynaecological disease. Cochrane Database Syst Rev. 2006;19(2):CD003677.

5. Meikle SF, Nugent EW, Orleans M. Complications and recovery from laparoscopy-assisted vaginal hysterectomy compared with abdominal and vaginal hysterectomy. Obstet. 1997;89(2):304-11.

6. Davies A, Vizza E, Bournas N, O'Connor H, Magos A. How to increase the proportion of hysterectomies performed vaginally. Am J Obstet Gynecol. 1998;179(4):1008-12.

7. Reich H. Total laparoscopic hysterectomy: indications, techniques and outcomes. Curr Opin Obstet Gynecol. 2007;19:337-44.

8. Einarsson JI, Suzuki Y. Total laparoscopic hysterectomy: 10 steps toward a successful procedure. Rev Obstet Gynecol. 2009;2(1):57-64.

9. Mukhopadhaya N, Manyonda IT. The hysterectomy story in the United Kingdom. J Midlife Health. 2013;4(1):40-1.

10. Broder MS, Kanouse DE, Mittman BS, Bernstein SJ. The appropriateness of recommendations for hysterectomy. Obstetrics and Gynecology. 2000;95(2):199-205.

11. Qamar-Ur-Nisa H, Habibullah, Memon F, Shaikh TA, Memon Z. Hysterectomies: an audit at a tertiary care hospital. The Professional Medical Journal. 2011;18(1):46-50.

12. Olive DL, Parker WH, Cooper JM, Levine RL. The AAGL classification system for laparoscopic 
hysterectomy. J Am Assoc Gynecol Laparosc. 2000;7(1):9-15.

13. Krebs HB, Helmkamp BF. Transverse periumbilical incision in the massively obese patient. Obstet Gynecol. 1984;63:241-5.

14. Pitkin RM. Abdominal hysterectomy in obese women. Surg Gynecol Obstet. 1976;142:532-6.

15. Nawfal AK, Orady M, Eisenstein D, Wegienka G. Effect of body mass index on robotic-assisted total laparoscopic hysterectomy. J Minim Invasive Gynecol. 2011;18(3):328-32.

16. O'Hanlan KA, Lopez L, Dibble SL, Garnier AC, Huang GS, Leuchtenberger M. Total laparoscopic hysterectomy: body mass index and outcomes. Obstet Gynecol. 2003;102(6):1384-92.

17. Pol G, Bobin L, Maciołek-Blewniewska G, Malinowski A. Operating time of laparoscopically assisted vaginal hysterectomy (LAVH) the causative factors and the course of the postoperative period. Ginekol Pol. 2007;78(3):204-9.

18. Clayton RD. Hysterectomy. Best Pract Res Clin Obstet Gynaecol. 2006;20(1):73-87.

19. Leonard F, Chopin N, Borghese B, Fotso A, Foulot $\mathrm{H}$, Coste J, et al. Total laparoscopic hysterectomy: preoperative risk factors for conversion to laparotomy. J Minim Invasive Gynecol. 2005;12(4):312-7.

20. Wattiez A, Soriano D, Cohen SB, Nervo P, Canis M, Botchorishvili R, et al. The learning curve of total laparoscopic hysterectomy: comparative analysis of 1647 cases. J Am Assoc Gynecol Laparosc. 2002;9(3):339-45.

21. Aniuliene R, Varzgaliene L, Varzgalis M. A comparative analysis of hysterectomies. Medicina Kaunas. 2007;43(2):118-24.

Cite this article as: Kiran TU, Katke RD. Minimally invasive hysterectomy for benign disease: our experience study. Int J Reprod Contracept Obstet Gynecol 2016;5:2372-6. 